\section{Glasgow is record breaker}

It has been announced that the 'world's biggest smile' created by Glasgow's Dental School, reported in the BDJ in July (2017; 223: 71), has been verified by Guinness World Records as a new world record for the world's biggest ever smile.

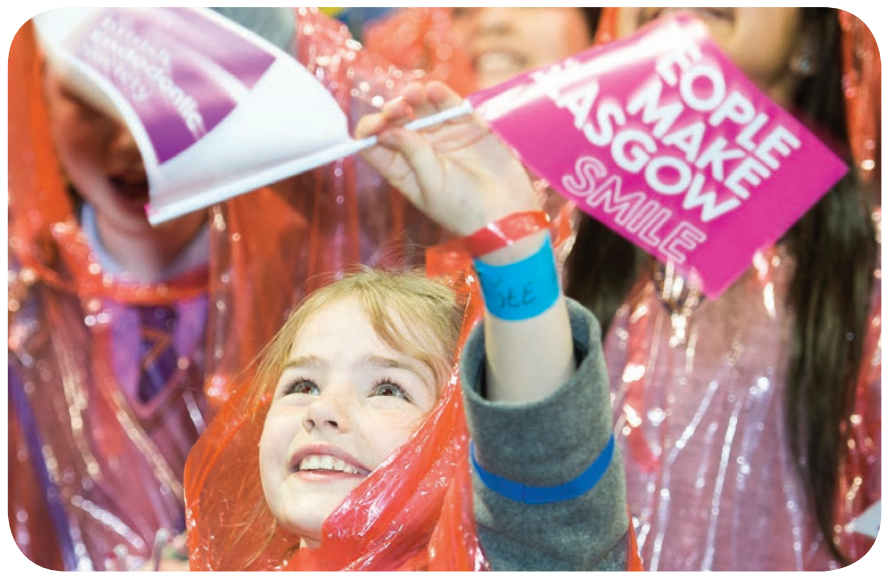

\section{South Mercia Branch Presidential Study Day}

Sandip Popat, President of the South Mercia Branch of the British Dental Association, is holding a Joint Clinical and DCP Study Day and Dinner at Rushton Hall in Kettering, NN14, on Friday 15 September 2017, starting at 9 am and with a presidential dinner at $7.30 \mathrm{pm}$.

The theme of the Clinical Day is 'What happens when it goes wrong' and for the DCP Day: 'Learning well, working well: Capturing effective learning and meeting professional requirements'. Speakers for dentist attendees include Paul Baker, Anthony Summerwill, Stephen Cawte and Raj Rattan; for the DCPs, Laurence Skermer, Alex Keir-Rawlings, Emma Riley, Michele Nevitt, Simon Tucker and Elaine Tilling.

For further information and to book, email southmerciabda@ gmail.com by Friday 1 September 2017.

\section{Volunteers needed for Uganda this September}

The charity HOPE B-Lit is urgently looking for volunteers to help carry out a Health \& Wellness Programme in Uganda from 19-23 September 2017.

HOPE has over six years' experience in designing initiatives in Asia and the USA and is now planning to visit Africa. It will provide oral care for around 5,000 children in Uganda. The Smile Dental Camp will screen children for dental disease; carry out advanced oral treatment including ultrasonic scaling, GIC composite fillings, pit and fissure sealants and tooth extractions; and provide dental care health cards and oral health education.

If you are interested in volunteering, visit http://www.hopeblit. com/uganda2017.html.

\section{Are you a periodontal researcher?}

Applications are invited to the John Zamet Memorial Prize in Periodontal Research, offered in association with the Alpha Omega London Chapter and Charitable Trust, with a closing date of 31 December 2017.

The prize has been established to recognise and commemorate the significant contribution made to clinical periodontology by the late Dr John Zamet. Dr Zamet was an Honorary Consultant and Senior Research Fellow at the UCL Eastman Dental Institute, a Past President and Honorary Member of the British Society of Periodontology and the founder Chairman and a Trustee of the Alpha Omega London Chapter and Charitable Trust.

Applications are open to all UK-based postgraduate dental students studying for a Master's degree or $\mathrm{PhD}$ who are undertaking or who have recently completed original research associated with clinical periodontology. The prize will be awarded biennially with a value of $£ 2,000$.

More information can be found at: http://alphaomegauk.co.uk/ john-zamet-prize/.

\section{Honours, awards, appointments}

\section{Benevolent Fund Chairman}

Professor Ros Keeton was appointed to the role of Chairman of the BDA Benevolent Fund at the Annual General Meeting on 30 June 2017. Professor Keeton has been a Trustee of the charity since 2008 and Treasurer since 2012. Professor Keeton is an experienced NHS Chief Executive and healthcare leader who combines a dental background with substantial leadership experience across the full range of healthcare settings.

\section{GDC Council members}

The following new General Dental Council members will take up their posts on 1 October 2017:

- Anne Heal, Crispin Passmore, Sheila Kumar, Terry Babbs - all lay members

- Caroline Logan, registrant member (dental technician)

- Jeyanthi John, registrant member (dentist).

Margaret Kellett and Catherine Brady, both dentist registrant members, have both been appointed for a second term of office. Outgoing Council members include Alan MacDonald, David Smith, Jayendra Patel, Neil Stevenson and Rosemary Carter.

\section{Jamie Newlands}

Dentist Jamie Newlands has died aged 39. Dr Newlands was named Scotland's Best Young Dentist in 2009 and received a Best Dentist award in 2010. He is survived by his wife and the couple's young daughter. 